\title{
ASSESSMENT OF THE IMPACT OF PROBE HEAD HYSTERESIS ON THE ACCURACY OF FIVE-AXIS COORDINATE MEASURING SYSTEMS
}

\author{
Piotr Gąska', Maciej Gruza' , Adam Gąska', Wiktor Harmatys' ${ }^{1}$ Jerzy Sładek' \\ 1 Cracow University of Technology, Faculty of Mechanical Engineering, Laboratory of Coordinate Metrology \\ (M-10), al. Jana Pawła II 37, 31-864 Cracow, Poland, e-mail: piotr.gaska@pk.edu.pl,gruzam@interia.pl,agaska@ \\ mech.pk.edu.pl,wiktorharmatys@gmail.com, sladek@mech.pk.edu.pl
}

Received: 2017.05.15

Accepted: 2017.08.01

Published: 2017.09.03

\begin{abstract}
One of the factors affecting the accuracy of Coordinate Measuring Systems is hysteresis of a probe head. It is important especially in case of touch trigger probes and should be taken into account during the determination of probing strategy. In this article, the authors try to assess how this phenomenon affects the accuracy of five axis coordinate systems which utilize articulating probe head. Such systems allow to measure point coordinates using rotary movements of the head what introduces changes to the probing process. The experiments presented in this paper are based on multiple measurements of the reference elements such as gauge blocks and standard ring.
\end{abstract}

Keywords: articulating probe head, hysteresis, accuracy, CMM.

\section{INTRODUCTION}

The growing consumption and rapidly changing market trends formulate new demands for industry. They include the postulate of production process acceleration which can be achieved in many different ways $[11,12]$. In the field of the quality control, time savings can be attained for example by implementing in-process measurements which establish closer loop between the manufacturing process and quality control. Another approach includes improvement of the existing measuring instruments so they can meet new challenges, or development of the new devices. Both mentioned concepts could be observed in Coordinate Metrology over the recent years. The development of contactless techniques allow to compare almost whole surface of measured object directly with its CAD model. Computed Tomography goes even further by enabling non-destructive measurements of object interior. However, still the basic tool of Coordinate Measuring Technique is Coordinate Measuring Machine (CMM). Measurement acceleration in this case can be obtained for example by using new lighter materials in CMM construction or by the development of different types of probe heads. Interesting solution that fits into considered trend is a five-axis coordinate measuring system which utilize articulating probe head. In such solution the machine kinematics is the same as in standard CMMs and the machine movable parts can realize shifts towards three mutually perpendicular directions. Additional two axes mentioned in the name of the measuring system refers to the rotary movement realized by probe head which can be used during measurements. In classic CMMs, even those which utilizes articulated probe heads, the orientation of probe has to be declared and calibrated before measurement and can be changed only between actual measurements. In five-axis coordinate measuring systems orientation of the probe can be modified freely (within measuring range of probe head) without additional calibrations and what is even more important measurements can be performed only using rotational movements of probe. Probes meet in five-axis measuring systems can be dived into 


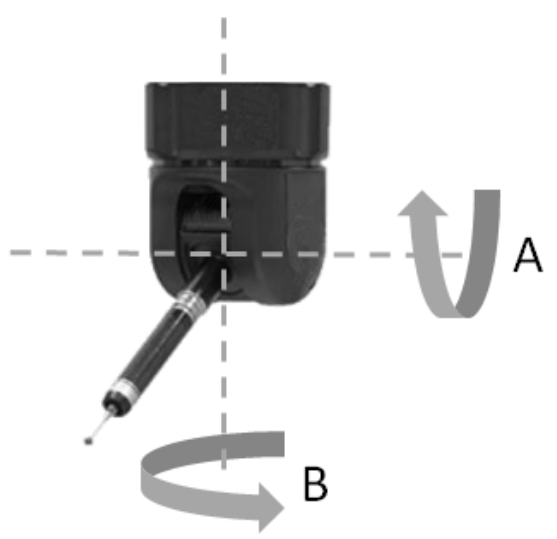

Fig. 1. The probe head used in five-axis measuring systems with marked axis of revolution

touch-trigger probes and measuring ones. In the first group the deflection of the stylus attached to the probe, triggers the signal which informs the machine driver about the contact with the measuring surface. After the appearance of the impulse, the indications of the linear scales for each axis are read, which are then processed to measured coordinates (after the appliance of appropriate radial correction of the tip ball). However, the size of stylus deflection is not measured and it differs with change in the approach direction, measuring speed, force etc. In five-axis measuring systems the touch-trigger probe is usually magnetically attached to the probe head which is responsible for changing and measuring the stylus orientation. The probe head can rotate around two mutually perpendicular axes. The producer of described probe heads marks the horizontal axis by letter A and vertical one by letter B (Fig. 1). The rotation around vertical axis is unlimited (although the indications vary between 0 and 360), while range of possible rotation about $\mathrm{A}$ axis is around 180. The same kinematic can be found in case of measuring heads used in five axis measuring systems. The difference is that measuring head gives also insight in stylus deflection. Thus, resultant measured coordinates are sum of values indicated by linear scales, angular read-outs of probe and measured probe deflection. Also the working principle of such probes is different. They utilize laser beam which is directed through the hollow stylus into the reflector attached closely to the tip ball. Probe deflection can be observed using the photo detector.

In both solutions mentioned above, the position of tip ball is determined using indications of linear scales and angular read-outs from probe head. It should also be noted that five-axis measuring systems are in fact redundant systems because the same position can be obtained with infinitive configurations of machine and probe. That fact introduces the problem of optimization of the measuring strategy which can have certain impact on the measurement result. It is only one of many questions arising around the issue of five-axis measuring systems accuracy. Because they are relatively new solution there are only few papers devoted to this topic, which are focused on such problems as influence of the angular orientation of the stylus on the probe errors [4] or influence of stylus length on measurement accuracy [3]. Another important factor which may affect the accuracy of five-axis measurements is probe head hysteresis.

\section{PROBE HEAD HYSTERESIS}

Hysteresis is a term used to describe the fact that system response to certain input depends on the order of proceeding inputs [10] or generally, on the history of regarded system. This phenomenon can be observed for majority of measuring systems, and can be found also in case of probing systems meet in Coordinate Metrology. This subject for standard CMMs was described in [2, $5,7,10]$. The methodology presented in listed papers utilizes the special research station capable of measuring the probe pre-travel depending on the probing vector direction. The probe is tested separately from CMM and it is lean by the external mechanism which allow to measure its deflection with high accuracy. The term pretravel $[2,7,8,9,10]$ originates from the principle of probing. Ideally, the coordinates of probing point indicated by the machine should be the same as the coordinates of point in which the tip contacts measured surface. However, the working principle of probes, especially touch-trigger ones, requires the machine movement after the contact occurrence. In touch trigger probes three arms, oriented relative to each other by 120 degrees, are combined with the stylus and rely on the prisms and whole structure is held in neutral position by the spring. When one of the arms lose contact with the prism, the electrical circuit brakes what generates an impulse for machine driver. This implies that probe during the measurement must be deflected enough to overcome the spring force. The path that machine will com- 
plete from the contact with measured surface until the impulse appears is called pre-travel. The value of pre-travel is different for various probing directions, moreover it depends on the used stylus length, probing speed or materials and weight of CMM parts. The hysteresis of touchtrigger probe is related to the fact that after each measurement (probe deflection) the probe should return, under the spring force, to the neutral position, the position with which probe starts contact process. Any distortions in return process, and in turn in neutral position, would lead to the changes in triggering position (the position of probe when the impulse appear).

In $[2,10]$ three parameters were defined in order to quantitatively describe probes hysteresis: hysteresis of triggering point, the hysteresis of neutral position of the stylus tip and the pretravel hysteresis. The experiments described in [10] shows that triggering point can be moved over 2 um depending on the preceding point measurement direction. The discussed methodology gives deep insight into the probe performance but it requires additional research station, moreover, information obtained using this method cannot be easily transferred to real measurement on CMM (among others because most often during the actual measurements the probe which is mounted on the machine's quill moves through the measuring volume and the measured object is fixed). Another approach meet in experiments focused on probe heads accuracy is methodology based on measurements of reference objects of known curvature, mostly standard rings or spheres $[1,8]$. Assuming that shape deviation of used object is negligible considering the accuracy of the tested probe (shape deviation is smaller than $0.2 *$ PFTU defined according to [6]) and the dimensions of reference object is small enough to minimize the kinematic influences of CMM on the measurement result (they should be less than 30 $\mathrm{mm}$ ), the errors obtained during experiment can be attributed to the probe head. The Probe Error (PE) which can be observed using this method is a sum of many factors such as: deformations of tip ball occurring during contact process, stylus deformation under the measuring force, influence of tip ball shape deviations or probe pre-travel. The function of probe error (PEF) can be defined in dependence on the measurement direction and can be used to find the directions in which probe gives the best/worst results and to correct the probe indications. It can be also used to compare how dif-

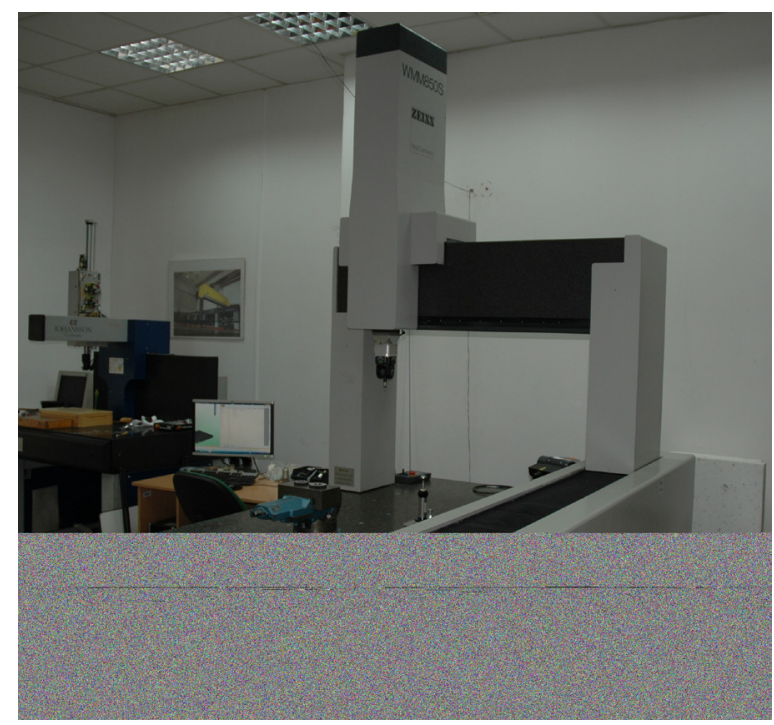

Fig. 2. The Zeiss WMM850S machine equipped with Renishaw PH20 probe head

ferent factors affect the probe performance. The authors decided to use it in order to examine the hysteresis of five-axis measuring systems.

\section{EXPERIMENT AND RESULTS}

The experiments presented in this paper are based on the measurements of reference objects and comply with a guidelines for hysteresis designation presented in $[5,7]$. All described measurements were performed at LCM using Zeiss WMM850S machine (Fig. 2), equipped with Renishaw PH20 probe head, with touch trigger TP20 STD probe. Measuring volume of the device is $800 \backslash 1200 \backslash 700 \mathrm{~mm}$. The machine is located in the air-conditioned room, and the temperature during measurements varied between $19,5^{\circ} \mathrm{C}-20,5^{\circ} \mathrm{C}$.

The first stage of the experiment involve measurements of standard ring of $20 \mathrm{~mm}$ diameter which fulfils requirements formulated in previous section. The reference object was mounted in measuring volume of machine in such a way that the axis of ring is parallel to the $\mathrm{z}$-axis of machine. After designation of the local coordinate system linked with the main axis of ring, the inner circle was measured in 20 evenly distributed points, located in the half of ring height. All rings measurement described in this article were performed using only rotational movements of probe head. The measurement strategy is shown in the Fig. 3a along with coordinate system ( $\mathrm{Z}$-axis is designated by the axis of ring) used in all described ring measurements. This procedure will 


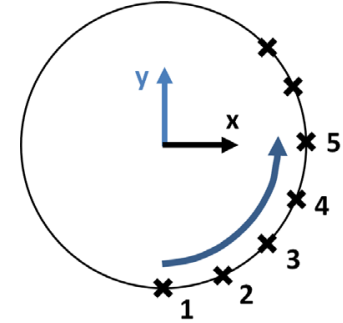

a)

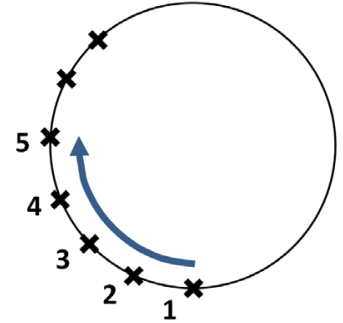

b)
Fig. 3. The measuring sequence for: a) Procedure 1 (with marked coordinate system used in all ring measurement); b) Procedure 2

be referred to as Procedure 1. The measurement was repeated 10 times to determine the mean value of PE and standards deviations corresponding to each measuring point. This data constitutes the set of reference values for further measurements. In next step measuring procedure was repeated but for reverse direction (Fig. 3b). This procedure will be named Procedure 2 .

During both described procedures TP20 probe deflects in the same direction, because firstly head rotates around the $\mathrm{B}$ axis, and then only the rotations around $\mathrm{A}$ axis are used during measurement. As a result TP20 probe for each point uses almost the same probing direction. To assess how TP20 probe contributes to the five-axis measuring systems hysteresis the third procedure (Procedure 3) was designed. During this stage of experiments the ring was measured in the same points but with different strategy (Fig. 4a). The subsequent measurements are performed for opposite side of the ring After measurement of the first point with certain A angle, the next point is measured by rotating head around $A$ axis until the probe contact the ring on the opposite side. Then the B angle is changed and the sequence is repeated. Such approach causes that following points aren't measured with the same TP20 deflection. Fourth procedure (Procedure 4) was developed to check how the changes in the B rotations affect the measurements re-

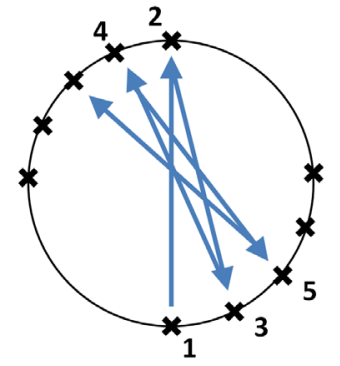

a)

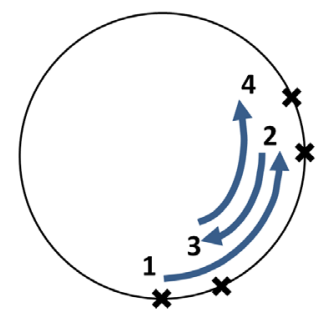

b)
Fig. 4. The measuring sequence for: a) Procedure 3; b) Procedure 4

sults. In this sequence (Fig. 4b) after measuring one point the $\mathrm{B}$ angle is changed by 90 degrees for next measurement and then rotated back by 72 degrees. In such a manner each point is measured with varying approach direction of B angle.

Then the results obtained for Procedures 2, 3 and 4 were compared with results received for reference Procedure 1. The hysteresis error was calculated for each measured point as a difference between PE obtained for measuring point in Procedure 1 and adequate point for other procedures. The maximum of absolute hysteresis error value and mean of absolute hysteresis error values for three considered cases were presented in Table 1. The results are shown also in Fig. 5 - 7.

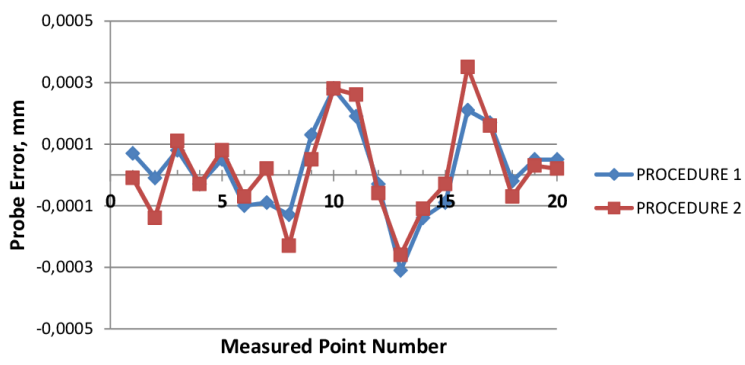

Fig. 5. The Probe Error obtained for each measured point in Procedures 1 and 2 (the points in Procedure 2 was matched with appropriate points from Procedure 1)

Table 1. The maximum of absolute hysteresis error value and mean of absolute hysteresis error values for reference rings measurements using different measuring procedures

\begin{tabular}{|c|c|c|}
\hline & $\begin{array}{c}\text { The maximum of absolute hysteresis } \\
\text { error value, } \mathbf{~ m m}\end{array}$ & $\begin{array}{c}\text { Mean of absolute hysteresis error values, } \\
\mathbf{~ m m}\end{array}$ \\
\hline Procedure 1 - Procedure 2 & 0,0001 & 0,0001 \\
\hline Procedure 1 - Procedure 3 & 0,0047 & 0,0016 \\
\hline Procedure 1 - Procedure 4 & 0,0005 & 0,0002 \\
\hline
\end{tabular}




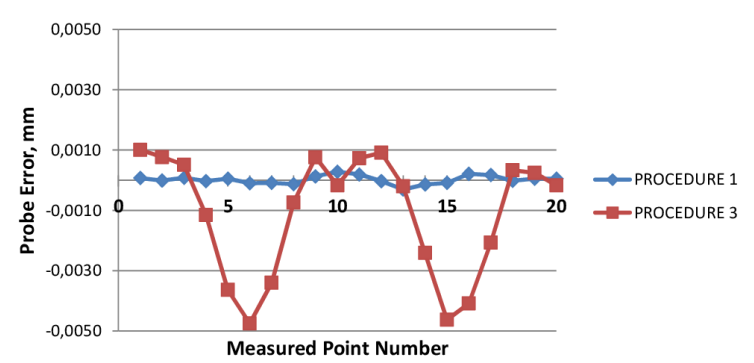

Fig. 6. The Probe Error obtained for each measured point in Procedures 1 and 3 (the points in Procedure 3 was matched with appropriate points from Procedure 1)

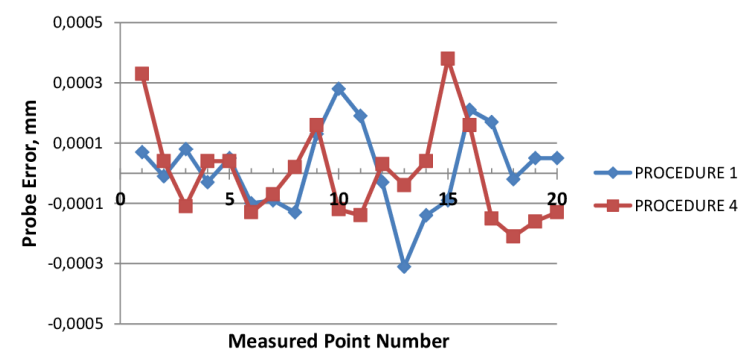

Fig. 7. The Probe Error obtained for each measured point in Procedures 1 and 4 (the points in Procedure 4 was matched with appropriate points from Procedure 1)

After the reference ring measurements authors decided to check the probe hysteresis using methodology described in [5]. In this case the probe hysteresis can be assessed by measuring specially arranged gauge blocks (Fig. 8). As can be seen the same distance could be measured with opposite probing directions.

The difference in obtained lengths is considered as hysteresis error. Authors decided to perform this test for five axis measuring system working both in standard 3 axis mode and utilizing rotary movements of head for points measurement. For both modes the measurement were repeated 10 times. The $24 \mathrm{~mm}$ gauge blocks was chosen to minimize influences of machine kinematics on 3-axis measurements. The maximum of absolute hysteresis error value and mean of absolute hysteresis error values are presented in Table 2.

\section{CONCLUSIONS}

Experiments have provided interesting results. The reference ring measurements show that used strategy can significantly affect the measurement result. The first two utilized proce-

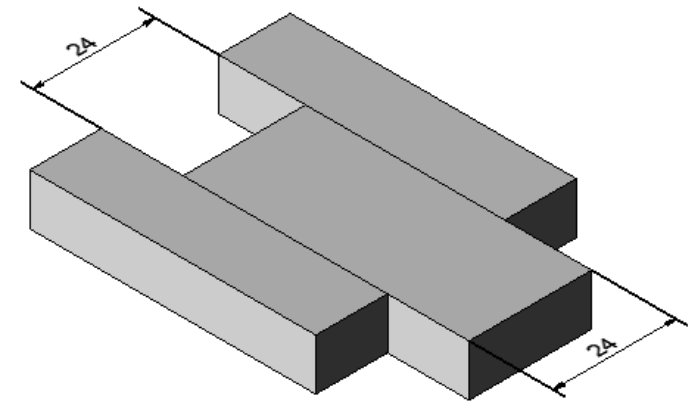

Fig. 8. The arrangement of gauge blocks used in measurements

dures give almost the same outcome. The bigger differences in measured PE values can be observed comparing Procedure 1 with Procedure 4 what may suggest that more precise results would be obtained without changing the direction of rotation around $\mathrm{B}$ axis. Measurements done according to Procedure 3 delivered the worst results. They indicate that big changes in the A angle direction made between subsequent measurements may have unfavorable influence on the measurements. What is responsible for such discrepancies? It is a question that surely demands additional research. Both the results presented on Fig. 6 and the results of second stage of experiments which involves gauge measurements leads to the conviction that change in the deflection direction of TP20 probe is important factor in this case.

What can also be concluded now basing on the results of standard ring measurements is that the most beneficial measuring strategies, in regard to measurement accuracy, are those that are set as default by the producer of probe head in the dedicated metrological software. Those are sequences in which the measurements of rotary features are done using regular increment of $\mathrm{B}$ axis angle in clockwise or counter clockwise direction.

Table 2. The maximum of absolute hysteresis error value and mean of absolute hysteresis error values for gauge measurements using different work mode

\begin{tabular}{|c|c|c|}
\hline & $\begin{array}{c}\text { The maximum of } \\
\text { absolute hysteresis } \\
\text { error value, } \mathbf{~ m m}\end{array}$ & $\begin{array}{c}\text { Mean of abso- } \\
\text { lute hysteresis } \\
\text { error values, } \mathbf{~ m m}\end{array}$ \\
\hline $\begin{array}{c}\text { CMM } \\
\text { measurements } \\
\text { (3-axis mode) }\end{array}$ & 0,0030 & 0,0025 \\
\hline $\begin{array}{c}\text { Head } \\
\text { measurements }\end{array}$ & 0,0012 & 0,0005 \\
\hline
\end{tabular}


The gauge measurements allow to draw more definitive conclusions. The usage of rotary movements during measurement ensured greater consistency of results regardless approach directions on measuring points being used. Limitation of the CMM movements is beneficial for the operation of the measuring head, reducing its hysteresis error (defined according to [5]).

In conclusion, it should be noted that hysteresis is a factor influencing the accuracy of a fiveaxis system, but it can be minimized by appropriate planning of the measurement strategy.

\section{Acknowledgments}

Reported research was realized as part of a project financed by National Science Centre, Poland, grant no. 2015/17/D/ST8/01280.

\section{REFERENCES}

1. Cauchick-Miguel P. A., King T. G. Factors which influence CMM touch trigger probe performance. International Journal of Machine Tools and Manufacture, 38(4), 1998, 363-374.

2. Dobosz, M., Woźniak, A. CMM touch trigger probes testing using a reference axis. Precision Engineering, 29, 2005, 281-289.

3. Gąska A., Gąska P., Gruza M., Ostrowska K., Stadek J. Assessment Of The Impact Of Stylus Length On Measurement Accuracy For Five-Axis Coordinate Measuring Systems. Proc. of 12th International Scientific Conference Coordinate Measuring Technique, Szczyrk, Polska 2016, 1-5.
4. Gąska A., Gąska P., Gruza M. Simulation Model for Correction and Modeling of Probe Head Errors in Five-Axis Coordinate Systems. Applied Sciences, 6(5), 2016.

5. Hocken R. J., Pereira P. H. Coordinate Measuring Machines and Systems, Second Edition. CRC Press, 2012.

6. ISO 10360-5:2010: Geometrical product specifications (GPS) - Acceptance and reverification tests for coordinate measuring machines (CMM) - Part 5: CMMs using single and multiple stylus contacting probing systems, Second edition, 2010.

7. Ratajczyk E., Woźniak A. Współrzędnościowe systemy pomiarowe. Oficyna Wydawnicza Politechniki Warszawskiej, 2016.

8. Sładek, J: Coordinate Metrology: Accuracy of Systems and Measurements. Springer, 2016.

9. Weckenmann A., Estler T., Peggs G., McMurtry D.: Probing Systems in Dimensional Metrology. CIRP Annals-Manufacturing Technology, 53(2), 2004, 657-684.

10. Woźniak A.: Dokładność stykowych głowic pomiarowych maszyn współrzędnościowych. Oficyna Wydawnicza Politechniki Warszawskiej, 2010.

11.Zaleski K., A study on the properties of surface - active fluids used in burnishing and shot peening processes, Advances in Science and Technology Research Journal, 10(31) 2016, 235-239.

12. Zagórski I., Kuczmaszewski J., Study of chip ignition and chip morphology after milling of magnesium alloys. Advances in Science and Technology Research Journal, 10 (32), 2016, 101-108. 